\title{
Parlez-vous français? Episodic and Semantic Feeling of Knowing in
} Aging

\author{
Suzannah M. Morson ${ }^{1}$, Chris J. A. Moulin ${ }^{2}$, Jelena Havelka ${ }^{1} \&$ Celine Souchay ${ }^{2}$ \\ ${ }^{1}$ Institute of Psychological Sciences, University of Leeds, Leeds, UK \\ ${ }^{2}$ LEAD UMR CNRS 5022, Pôle AAFE, Esplanade Erasme, Université de Bourgogne, 21065 Dijon, France \\ Correspondence: Celine Souchay, LEAD UMR CNRS 5022, Pôle AAFE, Esplanade Erasme, Université de \\ Bourgogne, 21065 Dijon, France. E-mail: celine.souchay@u-bourgogne.fr
}

\author{
Received: February 4, $2014 \quad$ Accepted: May 4, $2014 \quad$ Online Published: May 26, 2014 \\ doi:10.5539/ijps.v6n2p138 URL: http://dx.doi.org/10.5539/ijps.v6n2p138
}

\begin{abstract}
As well as memory performance, the sensations and experiences that accompany memory retrieval can be informative regarding changes to memory that occur with aging. One such experience is the Feeling of Knowing (FOK), the sensation that an item which has failed to be recalled is nonetheless stored within the memory system, though temporarily unavailable. Older adults consistently show preserved FOK accuracy for semantic information. However, measures of FOK accuracy in episodic memory tasks have yielded inconsistent findings. The present study used a novel language translation paradigm to assess the effect of age on semantic and episodic FOK judgments, and to examine the impact of repeated learning trials on episodic FOKs. As expected, no age effect was found for semantic FOK judgments. For episodic judgments, older adults' only were found to have chance levels of performance: FOK judgments in the older adult group were not predictive of future memory performance. Repeated learning trials led to comparable improvements in FOK accuracy between the two age groups, although older adults remained at chance until after the third learning trial. Results are interpreted within recent memory and metamemory frameworks.
\end{abstract}

Keywords: feeling of knowing (FOK), aging, metacognition, language learning

\section{Introduction}

Episodic memory tasks require the acquisition of declarative information during a specified learning session for later reproduction. In contrast, semantic memory tasks rely on knowledge already obtained which is not associated with a specific learning episode (Tulving, 1985). Aging has repeatedly been shown to have dissociable effects on each type of memory, with episodic memory declining while semantic memory is preserved (see Anderson \& Craik, 2000; Zacks et al., 2000 for reviews). However, the impact of age on the monitoring and control processes that regulate memory performance (termed metacognition; Nelson \& Narens 1990, 1994) is less clear. One such monitoring process is the feeling of knowing (FOK \& Hart, 1965), the sensation that information currently irretrievable is nonetheless stored within the memory system and could be later retrieved. Feeling of knowing judgments require participants to make a prediction of future memory performance for currently unrecalled items and, despite being unable to retrieve the specific memory at the time of making the judgment, participants are typically accurate at predicting future retrieval (e.g. Hart, 1965; Nelson et al., 1982; Schacter, 1983). The feeling of knowing paradigm can be applied to both semantic (for example general knowledge questions, Nelson et al., 1984) and episodic information (for example word pairs, Schacter, 1983), allowing assessment of metacognition for both memory systems.

In aging, semantic FOKs (i.e. FOKs obtained during a semantic memory task) have been examined for general knowledge information (Marquié \& Huet, 2000; Souchay et al., 2007) and rare word definitions (Allen-Burge \& Storandt, 2000; Butterfield et al., 1988), with no age effects found. For semantic memory, older adults are thus able to predict future memory performance for unrecalled items with the same degree of accuracy as young adults. Episodic FOKs are judgments for unrecalled items in an episodic memory test. Typically, this involves learning arbitrary paired associates, then cueing memory with the first word of the pair and asking the participant to recall the second word (e.g. Maki, 1999; Schacter, 1983). The impact of aging on FOK for these episodic memory tasks is less clear. Despite consistent deficits in episodic memory, preservation of episodic FOK ratings has been reported (Hertzog et al., 2010; MacLaverty \& Hertzog, 2009), implying that older adults are aware of 
their lowered memory performance and incorporate this knowledge into their memory judgments. However, a number of studies have also found evidence of an impairment in episodic FOK accuracy (Perrotin et al., 2006; Souchay et al., 2000; Thomas et al., 2011). These later studies thus suggest that as memory performance declines, so does the ability to accurately monitor the contents of memory, leading to errors in judgments. With no clear explanation as to why such discrepancy has been found within the aging literature, the effect of aging on episodic FOK accuracy has yet to be established. The novelty of the current research is that it allows comparison of semantic and episodic FOKs in aging within a single task, with the same participants and the same materials, by utilising a language learning paradigm.

Many findings support the existence of a selective age effect on episodic FOK accuracy. First of all, episodic and semantic memory differ according to the subjective states experienced during retrieval (Tulving, 1985). Episodic memory is associated with "remembering", the retrieval of images, thoughts and feelings in conjunction with the memory itself. This recovery of associated details in addition to the memory is also termed recollection or recollective experience (Yonelinas, 2002). In contrast, semantic memory is associated with "knowing", retrieval of the memory in isolation. A recent development in the metacognition literature suggests close links between metacognitive judgments and subjective states associated with retrieval. For example, using the Remember/Know procedure (Tulving, 1985), Hicks and Marsh (2002) observed a strong relationship between FOK judgments and subjective states of awareness: higher FOKs were associated with more Remember responses on a subsequent recognition task. This would suggest that the cues available during failed recall are predictive not only of future recognition but also of recollective experience, a conclusion supported by Souchay et al.'s (2007) observation of significant correlations between FOK predictions and Remember responses. The relationship between recollective experience and FOK accuracy is especially important regarding aging, where both subjective measures (e.g. Remember/Know: Bugaiska et al., 2007; Friedman et al., 2010) and objective measures (e.g. source memory tasks: Henkel et al., 1998; Thomas et al., 2011) indicate a recollective deficit in older adults. If recollective experience and FOK predictions are closely linked, impairments in recollective experience would have a negative effect on FOK judgments. Indeed, Souchay et al. (2007) observed that partialling out recollection removed the age deficit in FOK responding, and Thomas et al. (2011) were also able to remove the FOK deficit in aging by asking older adults to retrieve contextual information before giving FOK judgments.

In conjunction with recollective deficits, consideration of the brain locus of FOK also provides support to the potential age effect observed on Episodic FOK judgments. The role of the frontal lobes in episodic FOK judgments has in particular been highlighted by studies in neuroimaging, aging, and in patient work. Research involving frontal lobe patients has repeatedly shown an impairment in episodic FOK accuracy (Janowsky et al., 1989; Pinon et al., 2005; Schnyer et al., 2004; but see Pannu et al., 2005), indicating that this region plays a vital role in assessing future retrieval for episodic information. In aging, a clear link has been demonstrated between executive function and episodic FOK accuracy (Perrotin et al., 2006; Perrotin et al., 2008; Souchay et al., 2000), with deficits in executive function associated with deficits in episodic FOK resolution. This again emphasises the importance of the frontal lobes for successful monitoring of memory, as executive function is primarily associated to frontal lobe regions (Courtney et al., 1996; Gold et al., 1996; Jonides et al., 1993; McCarthy et al., 1994; Owen et al., 1996; Petrides et al., 1993; Smith \& Jonides, 1999; Smith et al., 1995; Sweeney et al., 1996), which show the earliest and greatest age-related atrophy (Raz, 2000).

However, despite evidence to support the hypothesis of selective impairment of episodic FOK accuracy, research has also indicated preserved accuracy in aging (Hertzog et al., 2010; MacLaverty \& Hertzog, 2009). In this context, the memory constraint hypothesis (Hertzog et al., 2010) suggests that episodic FOK accuracy is dependent primarily on the quality of the underlying memory processes. This relates to the accessibility account (Koriat, 1993, 1997) which places the emphasis on the target, with FOK judgments being informed by the retrieval of partial information related to the target in question. In other words, if the memory is poorly encoded, less partial information will be retrieved both in terms of quality and quantity, reducing the accuracy of the FOK judgment (see Perfect \& Stollery, 1993 for a similar argument). Therefore observed age effects on episodic FOK accuracy are not a reflection of impaired metacognitive ability per se, but are a further demonstration of impaired episodic memory in aging. Indeed, by equating young and older adults' memory performance using variable delays, Hertzog et al. (2010) were able to elucidate episodic FOK judgments of equivalent accuracy for the two age groups.

With support for both impairment and preservation of episodic FOK accuracy, a novel approach is needed to examine the effect of age on semantic and episodic FOKs. To date, only one study has evaluated semantic and episodic FOK within the same participants. Souchay et al. (2007) observed comparable FOK performance in 
young and older adults when making FOKs for general knowledge questions. However, when testing the same participants on word pair learning, the older adults were significantly less accurate in their FOK predictions. In addition to using the same participants for each task, Souchay et al. also used the same target items. For example, in the semantic task the question may have been "What is the subject of Magritte's famous surrealist painting, 'La Trahison?', the answer being 'Pipe". In the episodic task, an unrelated cue would be paired with the same item, e.g. Birthday-Pipe. The intrinsic properties of the target words, such as word frequency, could not therefore be inadvertently influencing the FOK judgments. However, the influence of task characteristics could still be a factor (Koriat, 1997), with the cue type changing from conceptual (semantic) to contextual (episodic). The present study aims to remove this potential confound by using a language translation paradigm. Translation tasks have previously been used to examine semantic FOK accuracy in young adults (Koriat, 1975; Peynircioğlu \& Tekcan, 2000). A natural extension which has not been followed to date is to combine this with an episodic task: following a semantic FOK assessment of translations, allow participants to learn those items which they do not know the correct translation for, thereby assessing episodic FOKs. This paradigm provides a unique methodology with high control over a number of variables which may influence FOK accuracy, including materials, task presentation, and individual differences in participants. In the current study, French-English translations were used to assess semantic and episodic FOK. The French language is one of the most commonly encountered within the UK, with over $94 \%$ of primary schools teaching French as a second language (Department for Education and Skills, 2003) and with the regular use of French words (e.g. déjà vu) within the English language. This level of familiarity with the French language should therefore provide a suitable level of semantic knowledge for the English translations of common French words to allow assessment within a semantic memory and FOK task. Following an assessment of semantic memory, unknown French words can then be re-presented with the English translations, thereby providing materials for an episodic memory and FOK task. This not only allows semantic and episodic FOKs to be cued by the same question ("what is the English translation") but has an advantage over the general knowledge paradigm by using the same cue for each semantic item, further negating the impact of context. Previous research has shown that during self-regulated language learning young and older adults select translations to study in a similar fashion, removing selection strategy as a possible confound (Price et al., 2010). Finally, the proposed paradigm allows an additional test of the memory constraint hypothesis via completion of multiple learning trials. Critically, repeated learning trials should benefit both young and older adults by increasing the quality of encoding, therefore also increasing FOK accuracy. This learning effect has previously been observed in young (Carroll \& Nelson, 1993; Nelson et al., 1982) and older adults (Hertzog et al., 2010). In sum, if the reported age deficit in episodic FOK accuracy is a consequence of poor encoding, we should observe both memory and FOK deficits in older adults compared to young adults for the episodic measures, but also improvements in episodic memory and FOK over the learning trials.

\section{Method}

\subsection{Participants}

Twenty-nine young adults and twenty-nine older adults were recruited for the study. Data from 2 young adults and 1 older adult were discarded due to high levels of performance on the final trial (see below). Data from a further 6 older adults were discarded due to fatigue leading to incomplete data. The remaining sample contained twenty-seven young adults (age range $18-28, M=20.63, S D=3.07$ ) and twenty-two older adults (age range 62-84, $M=72.64, S D=5.88$ ). All participants in the older adult group attained scores on the Mini-Mental State Examination (MMSE, Folstein et al., 1975) above the cut off of $27(M=28.91, S D=1.11)$, and were not receiving medication which would affect cognitive function. The critical issue to control for within this task is the level of French education, therefore participants were asked to report how many years they had spent studying French. No significant differences were found (young adult $M=3.30, S D=2.23$; older adult $M=3.34$, $S D=2.33 ; t(47)=0.068, p=.946)$, indicating a similar level of expertise between the two age groups. All participants received more than 10 years of education, although young adults $(M=15.81, S D=1.96)$ reported significantly more years of education than older adults $(M=13.48, S D=3.23 ; t(47)=2.92, p=.006)$ (Note 1$)$. Participants received either course credit or were unpaid volunteers, and the research was approved by the Institute of Psychological Sciences, University of Leeds, UK ethics committee.

\subsection{Materials}

A total of 80 French words and their English equivalents were used, all of which were nouns of three to nine letters long. An initial list of 100 medium to high frequency French words was selected from the Brulex database (Content et al., 1990) by two of the authors; one native English speaker and one native French speaker. These words were piloted on eight young adults who had studied French to a maximum of GCSE level (no more than 5 years) who did not take part in the study. From these 100, we selected 15 words that all pilot participants 
correctly translated (e.g. maison-house), 15 that some participants were able to translate (e.g. souris - mouse) and the remaining 50 words that no participants were able to translate (e.g. hibou - owl) to ensure sufficient scope for repeated learning trials. In all stages the French word was presented as the cue with the English translation as the required target. A standard recall-judgment-recognition procedure (Hart, 1965) was used to obtain FOK judgments. The recognition task was a four alternative forced choice task, with the same three distracters per target English translation used throughout the procedure (i.e. if the target was "mouse", then the distracters "forge", "slate" and "cigar" were used for each recognition test). The position of targets and distracters was randomised for each recognition test. Distracters were matched to the targets on Kucera-Francis written frequency (targets $M=144.02, S D=221.41$; distracters $M=140.80, S D=224.72$ ) and were not semantically related.

\subsection{Procedure}

Participants were tested individually in a single session.

\subsubsection{Semantic Feeling of Knowing}

The semantic FOK task used in the present study was similar to that of Peynircioğlu and Tekcan (2000). The aim here was to assess participants' ability to predict future recognition for non-translated items based purely on conceptual knowledge: participants had not yet been provided with the correct translations for the French words. Prior to any learning, the 80 French words were presented simultaneously, and participants were asked to write down the correct English translation next to the corresponding French word if known. FOKs were only obtained for errors of omission: if participants were unable to give a translation (either correct or incorrect), a dichotomous Yes/No FOK judgment (Souchay et al., 2000, 2007) was made as to whether they would recognise the correct translation for the French word from four options. In other words, when participants thought they would be able to recognize the target word in a later test, they were giving a "yes" FOK judgment, but a "no" FOK judgment when they thought that they would not be able to recognize the word. The four alternative forced choice recognition test was then administered. No time constraint was imposed for recall and recognition.

\subsubsection{Episodic Feeling of Knowing}

Immediately after the semantic trial, the episodic trials were begun (episodic trial 1). All 80 French words and their English translations were presented on a single sheet for learning: this was the first time during the experimental procedure that participants were shown the correct translations. The translations were shown for 160 seconds, with only the French word and the English translation provided to encourage episodic word-to-word associations to be made (Kroll \& Curley, 1988). Immediately after learning, a cued recall test was given followed by the four alternative forced choice recognition test, with FOKs obtained for errors of omission only as in the semantic FOK trial. The learning, recall and recognition were then repeated twice more on all 80 French words (episodic trials 2 and 3). As in the semantic trial, no time limit was imposed for recall and recognition. The key difference between the semantic and episodic trials is exposure to the correct translations: for the semantic trial, participants must rely on knowledge held prior to the experimental procedure to inform their FOK judgments, whereas for the episodic trials information provided during the experimental procedure (i.e. during the learning stage where the correct translations were provided) is used to inform the FOK.

\section{Results}

Results are presented in accordance with the two key aims of the study. First, memory and FOK data from the semantic and first episodic trial are reported, analysis of which allows examination of the potential age effect on semantic and episodic FOK accuracy. Second, memory and FOK data analysis are presented from the three episodic trials only, to allow examination of the effect of learning on episodic FOK accuracy in young and older adults.

\subsection{Semantic vs. Episodic (trial 1)}

\subsubsection{Memory}

A revised episodic score was calculated for each participant. Any items correctly recalled or recognised by a participant during the semantic stage would not require learning via word-to-word associations, therefore would not utilise episodic memory processes. These items were removed before calculating the participant's episodic memory and FOK measures, giving a proportion accuracy for the remaining "purely episodic" items.

Recall and recognition were each analysed using a 2 (age: young and older adults) x 2 (trial: semantic and episodic 1) mixed model analysis of variance (ANOVA). Means and standard deviations are presented in Table 1. The effect of age tended towards significance, $F(1,47)=3.36, p=.073, \mathrm{y}^{2}=0.07$, with older adults showing 
higher recall performance than young adults (Note 2). Recall was found to be significantly higher in the semantic than the episodic trial, $F(1,47)=18.78, p<.001, \mathrm{y}^{2}=0.29$. A significant interaction between age and trial, $F(1,47)=4.43, p=.041, \mathrm{y}^{2}=0.09$, indicated that, for the semantic trial, older adults showed greater recall performance than young adults. However, for the episodic trial, recall performance was comparable across the two age groups. A main effect of age was also observed in recognition performance, $F(1,47)=3.81, p=.057, \mathrm{y}^{2}$ $=0.08$, with higher recognition accuracy in older adults than young adults. No effect of trial, $F(1,47)=2.62, p$ $=.112, \mathrm{y}^{2}=0.08$, or interaction between age and trial, $F(1,47)=0.04, p=.846, \mathrm{y}^{2}=0.00$, was present.

Table 1.Mean memory performance scores across trials for each age group

\begin{tabular}{|c|c|c|c|}
\hline & & $\begin{array}{l}\text { Young adults }(\mathrm{n}=\mathbf{2 7}) \\
\text { M (SD) }\end{array}$ & $\begin{array}{l}\text { Older adults }(\mathrm{n}=22) \\
\text { M (SD) }\end{array}$ \\
\hline \multirow{4}{*}{$\begin{array}{l}\text { Proportion of items } \\
\text { correctly recalled }\end{array}$} & Semantic Trial & $0.25(0.16)$ & $0.36(0.17)$ \\
\hline & Episodic Trial 1 & $0.19(0.12)$ & $0.20(0.14)$ \\
\hline & Episodic Trial 2 & $0.45(0.18)$ & $0.44(0.24)$ \\
\hline & Episodic Trial 3 & $0.64(0.21)$ & $0.59(0.28)$ \\
\hline \multirow{4}{*}{$\begin{array}{l}\text { Proportion of items } \\
\text { correctly recognised }\end{array}$} & Semantic Trial & $0.64(0.11)$ & $0.71(0.15)$ \\
\hline & Episodic Trial 1 & $0.67(0.17)$ & $0.75(0.18)$ \\
\hline & Episodic Trial 2 & $0.87(0.14)$ & $0.87(0.14)$ \\
\hline & Episodic Trial 3 & $0.94(0.10)$ & $0.92(0.12)$ \\
\hline
\end{tabular}

\subsubsection{Feeling of Knowing}

Items where an attempt at translation had been made, whether correct or incorrect, were not included in the FOK analysis (Krinsky and Nelson, 1984). Therefore the semantic FOK included only those items which were not translated during the semantic trial, and the episodic FOK included only non-translated items during the episodic trial. A 2 (age) x 2 (semantic trial and episodic trial) x 2 (status: Yes FOK and No FOK) mixed model ANOVA was conducted to examine recognition accuracy for Yes FOKs and No FOKs (see Figure 1). Using this method, FOK accuracy would be indicated by higher levels of recognition for Yes FOK responses than for No FOK responses. A main effect of semantic and episodic trial was found, $F(1,40)=9.92, p=.003, \mathrm{n}^{2}=0.20$, with overall recognition higher in the episodic than the semantic trial. Critically, a main effect of status was observed, $F(1,40)=125.87, p<.001, \mathrm{y}^{2}=0.76$, whereby Yes FOKs showed greater recognition accuracy than No FOKs, as expected given accurate monitoring of non-recalled information. A significant interaction between trial type and status, $F(1,40)=22.32, p<.001, \mathrm{y}^{2}=0.36$, indicated that although recognition accuracy decreased slightly from semantic to episodic trials for Yes FOKs, recognition accuracy for No FOKs increased greatly from semantic to episodic. No main effect of age was present, $F(1,40)=0.49, p=.489, \mathrm{n}^{2}=0.01$. The age and status interaction was not significant, $F(1,40)=0.04, p=.845, \mathrm{y}^{2}=0.00$; suggesting that both groups' subsequent recognition was in keeping with their earlier FOK judgment. The interaction between age and trial type observed, $F(1,40)=4.08, p=.050, \mathrm{y}^{2}=0.09$, is in keeping with the interaction above, with young adults showing comparable recognition performance over semantic and episodic trials and older adults' performance higher in the episodic condition. No other interactions were detected (trial, age and status: $F(1,40)=0.57, p=.455, \mathrm{y}^{2}=$ $0.01)$. 


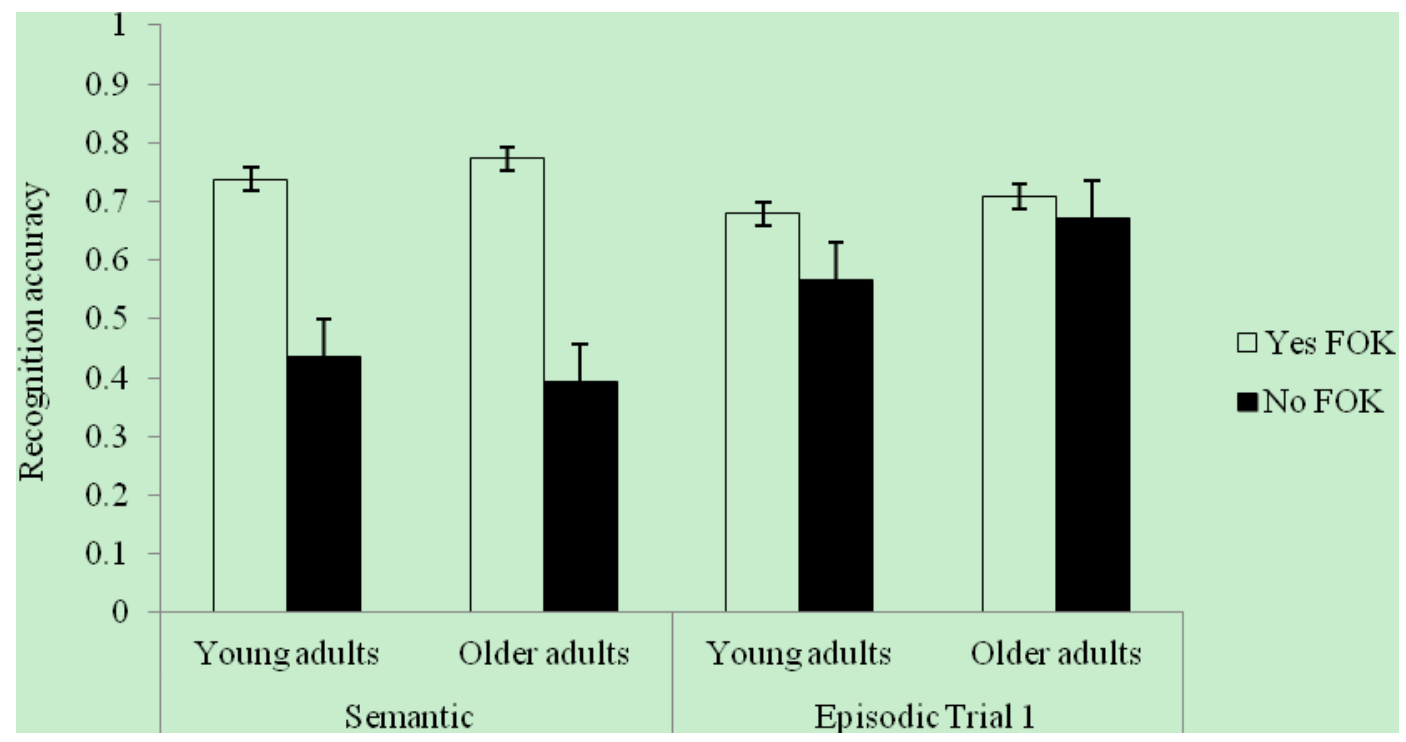

Figure 1. Recognition accuracy of items assigned Yes and No FOKs within each age group in the semantic trial and initial episodic trial. Error bars represent standard error

There has been considerable debate as to the most appropriate measure of FOK accuracy (Nelson, 1984; Schraw, 1995). The association between the Yes/No FOK judgment and recognition performance as obtained in the present study is most appropriately measured with the Goodman-Kruskal gamma correlation (Nelson, 1984; Schraw, 1995; Wright, 1996; see Masson and Rotello, 2009, for discussion of measures when using rating scales for FOK). Four possible outcomes can occur with a binary FOK: (a) correct recognition for Yes FOKs, (b) incorrect recognition for Yes FOKs, (c) correct recognition for No FOKs, and (d) incorrect recognition for No FOKs. The gamma correlation compares the proportion of correct predictions (a and d) to incorrect predictions (b and c). This leads to a coefficient ranging from 1 to -1 , with large positive values indicating a close relationship between FOK judgment and recognition, large negative values indicating an inverse relationship between FOKs and recognition, and values close to zero showing chance performance or guessing. However, gamma is undefined when two of the four possible outcomes (a, b, c, d) are equal to 0. Therefore, an adjusted gamma scored was calculated following Snodgrass and Corwin's (1988) recommendations (see Souchay et al., 2000, 2007), whereby 0.5 was added to each frequency and then divided by $\mathrm{N}+1$, where $\mathrm{N}$ is the number of judgments.

To establish if gamma scores were predictive of future recognition for each participant group for both episodic and semantic FOK tasks, one-sample t-tests were conducted. As can be seen in Table 2, for the semantic trial both young adults, $t(26)=8.94, p<.001$, and older adults, $t(21)=9.96, p<.001$, gamma scores were significantly above zero, indicating FOK judgments were diagnostic of future recognition. In addition, at the semantic trial, only one participant in each age group displayed a negative or zero gamma correlation (4\% of young adults and $5 \%$ of older adults), indicating that almost all participants were able to give predictions to a certain degree of accuracy. For the episodic trial, although the young adults gamma scores were again significantly above chance, $t(26)=3.97, p=.001$, the gamma scores for the older adults were not, $t(21)=0.84, p$ $=.413$. For the initial episodic FOK trial, older adults were not able to make accurate predictions of future recognition performance for unrecalled items. When examining individual gamma correlations, only $26 \%$ of young adults showed negative or zero gamma correlations, whereas $45 \%$ of older adults gave negative or zero gamma scores. In this initial episodic trial, almost half of the older adults tested were unable to accurately predict future recognition performance. Using a mixed model 2 (age) x 2 (trial) ANOVA, overall accuracy of FOK predictions showed a main effect of trial, $F(1,47)=25.51, p<.001, \mathrm{y}^{2}=0.35$, with higher gamma scores for the semantic trial than the episodic trial (see Table 2). However, no main effect of age was present, $F(1,47)=0.32, p$ $=.575, \mathrm{y}^{2}=0.01$, nor was an interaction between trial and age observed, $F(1,47)=2.33, p=.133, \mathrm{y}^{2}=0.05$. 
Table 2. Gamma correlations for young and older adults over all trials

\begin{tabular}{lllllll}
\hline & \multicolumn{2}{l}{ Young adults $(\boldsymbol{n}=\mathbf{2 7})$} & & \multicolumn{2}{c}{ Older adults $(\boldsymbol{n}=\mathbf{2 2})$} \\
\cline { 2 - 3 } \cline { 6 - 7 } & $M(S D)$ & Test against 0 & & $M(S D)$ & Test against 0 \\
\hline Semantic Trial gamma score & $.51(.30)$ & $\boldsymbol{p}<.001$ & & $.59(.28)$ & $\boldsymbol{p}<.001$ \\
Episodic Trial 1 gamma score & $.24(.32)$ & $\boldsymbol{p}=.001$ & & & $.09(.49)$ & $p=.413$ \\
Episodic Trial 2 gamma score & $.43(.46)$ & $\boldsymbol{p}<.001$ & & & $.24(.57)$ & $p=.065$ \\
Episodic Trial 3 gamma score & $.44(.42)$ & $\boldsymbol{p}<.001$ & & & $.29(.56)$ & $\boldsymbol{p}=.023$ \\
\hline
\end{tabular}

\subsection{Effect of Learning (Episodic Trials 1, 2 and 3)}

\subsubsection{Memory}

A 2 (age) x 3 (trial: episodic trial 1, 2, and 3) mixed model ANOVA was used to examine recall and recognition performance. As expected, a main effect of trial on recall performance was observed, $F(2,94)=199.96, p<.001$, $\mathrm{y}^{2}=0.81$, with recall increasing over the learning trials. No main effect of age, $F(1,47)=0.15, p=.698, \mathrm{y}^{2}=$ 0.00 , or interaction between age and trial, $F(2,94)=1.39, p=.253, \mathrm{y}^{2}=0.03$, were observed. Regarding recognition performance, again a main effect of trial was observed, $F(2,94)=130.55, p<.001, \mathrm{y}^{2}=0.74$, with recognition accuracy increasing over the trials. No main effect of age on recognition performance was shown, $F(1,47)=0.32, p=.575, \mathrm{n}^{2}=0.01$. However, an interaction between age and trial was observed, $F(2,94)=6.54$, $p=.002, \mathrm{y}^{2}=0.12$, with young adults showing a greater increase in recognition performance than older adults over the three learning trials.

\subsubsection{Feeling of Knowing}

A 2 (age) x 3 (trial) x 2 (status) mixed model ANOVA was conducted to examine recognition accuracy for Yes and No FOKs. A main effect of trial was observed, $F(2,34)=19.33, p<.001, \mathrm{y}^{2}=0.53$, with recognition increasing over trials. However, no main effect of status, $F(1,17)=2.52, p=.131, \mathrm{y}^{2}=0.13$, or age, $F(1,17)=$ $2.62, p=.124, \mathrm{y}^{2}=0.13$, was found. All interactions failed to reach significance (trial and age: $F(2,34)=0.11, p$ $=.897, \mathrm{y}^{2}=0.01 ;$ status and age: $F(1,17)=2.05, p=.170, \mathrm{y}^{2}=0.17$; trial and status: $F(2,34)=0.11, p=.900, \mathrm{y}^{2}$ $=0.01 ;$ trial, status and age: $\left.F(2,34)=0.30, p=.740, \mathrm{y}^{2}=0.02\right)$.

The predictive accuracy of gamma scores for each age group at each learning trial was first examined (see Table 2 for means). For the young adults, gamma scores at episodic trial $1, t(26)=3.97, p=.001$, episodic trial $2, t(26)$ $=4.85, p<.001$, and episodic trial $3, t(26)=5.50, p<.001$, were all significantly above chance, indicating that young adults were accurate in their predictions for future recognition. As described above, the older adult group were not above chance at the episodic trial 1 FOK judgment, $t(21)=0.84, p=.413$. By episodic trial 2 there is a trend towards significance, $t(21)=1.95, p=.065$; however, it is not until episodic trial 3 that older adults showed predictive accuracy for recognition performance, $t(21)=2.46, p=.023$. When looking at individual gamma scores, the comparative difficulty that older adults show in predicting future recognition is also evident. As stated above, $26 \%$ of young adults are at zero or below in their gamma correlations for the initial episodic trial. By trial 2 this has reduced slightly to $19 \%$, to then increase again to $22 \%$ by trial 3 . In contrast $45 \%$ of older adults were at or below zero on episodic trial 1, with the same percentage at zero or below for trial 2, and by trial $341 \%$ of the older adult group have negative or zero gammas. A larger proportion of the older adult group show either chance or inverse predictions of future memory performance compared to the young adult group. A 2 (age) x 3 (trial) mixed model ANOVA on adjusted gamma scores showed a tendency towards significance for age, $F(1,47)=2.91, p=.095, \mathrm{y}^{2}=0.06$, with young adults gamma scores greater than those of the older adults. A main effect of trial was also observed, $F(2,94)=3.46, p=.036, \mathrm{y}^{2}=0.07$, with increasing accuracy over the learning trials (see Table 2), indicating that participants became more accurate in their judgments with increased task experience. The effect of age also showed a No interaction between trial and age was observed, $F(2,94)=$ $0.03, p=.966, \mathrm{y}^{2}=0.00$.

\section{Discussion}

The novel use of a language learning paradigm in the current study allowed direct comparison of semantic and episodic FOK judgments in aging by removing the possible confounds of task type and target materials. As previously shown in the literature, the results demonstrated no effect of age on semantic FOK accuracy (Allen-Burge \& Storandt, 2000; Butterfield et al., 1988; Marquié \& Huet, 2000; Souchay et al., 2007). However, our findings suggest an age effect on episodic FOK accuracy. Indeed, when examining the individual gamma 
scores of participants, a greater proportion of the older adult group are at chance or show an inverse relationship between judgments and recognition in comparison to the young adults. In addition, when testing episodic FOK gamma correlations against zero in order to establish if judgments for each age group as a whole are above chance performance, older adults show impaired predictive accuracy at episodic trials 1 and 2. It is not before episodic trial 3 that episodic FOK gamma correlations in older adults finally raised above chance level. However, these findings need to be interpreted with caution. Although they suggest that older adults are to some extent unable to accurately judge which unrecalled items will be recognised within the episodic task, this impairment does not appear to be sufficiently strong to be detected within the ANOVA, possibly due to the higher variability in the older adult performance.

A clear finding is that both young and older adults showed comparable improvements in episodic FOK accuracy with learning; with repeated trials participants' ability to accurately monitor their memory increased as did memory performance. At first glance, these findings are consistent with the memory constraint hypothesis (MCH; Hertzog et al., 2010), whereby metacognitive accuracy is dependent on the quality of the memory processes. Indeed, for both groups FOK accuracy improves as memory performance increases. With no differences between age groups in semantic or episodic memory performance, young and older adults should have access to information of a similar quality on which to base their metacognitive judgments. When combined with the accessibility account (Koriat, 1993, 1997) whereby FOK judgments are based on the quality and quantity of partial information retrieved, similar levels of semantic and episodic FOK accuracy should therefore be observed. However, some of our findings suggest that age does affect episodic FOK accuracy despite no age effect on episodic memory performance. This leads to questions regarding the exact relationship between memory performance and FOK accuracy in aging. When examining the previous literature supporting an age effect on episodic FOK accuracy, the results of Souchay et al. $(2000,2007)$ and Perrotin et al. (2006) indicate that, in addition to FOK deficits, older adults exhibited significantly lower recall and recognition performance than young adults. Participants in the Thomas et al. (2011) study, where an age effect was also found on the episodic FOK accuracy, showed an age-related reduction in recall performance only; recognition accuracy was not impaired. Conversely, the results of MacLaverty and Hertzog (2009) showed no effect of age on episodic FOK accuracy. However, an age-related decline in recall and recognition performance was observed. These studies represent a mixed picture of the association between measures of memory performance and episodic FOK accuracy, with no clear pattern of whether impairment in one necessarily results in impairment of the other. Therefore although the $\mathrm{MCH}$ can to some extent explain why some studies report an age effect on episodic FOK accuracy, other cognitive or memory factors might interfere or contribute to this relationship, thus indicating that alternative explanations also need to be considered.

As noted above, the MCH (Hertzog et al., 2010) is linked closely to the target accessibility explanation of FOKs (Koriat, 1993, 1997): the greater the quality of the original encoding, the greater the quality of the partial information retrieved on which to base the FOK. Yet FOKs can also be informed by the familiarity of the cue (Reder \& Ritter, 1992; Schwartz \& Metcalfe, 1992). Koriat and Levy-Sadot (2001) conceptualised cue familiarity as providing the basis for rapid, preliminary FOK judgments, which, if familiarity is high enough, lead on to slower judgments based on target accessibility. In the current paradigm, the semantic FOK task can utilise both cue familiarity and target accessibility to inform the FOK judgments. Only those items for which the translation has been learned at some point in the past will look familiar. However, for the initial episodic trial, all items which are correctly recognised at the semantic trial have been removed from the analysis. This leaves only the items which participants do not know the meaning of, which could essentially be viewed as nonwords. Prior to learning, it is therefore reasonable to assume that these items will all have a similar but low level of familiarity. During learning, however, the familiarity of each of the cue words will change. For example, if a participant reads the unknown translation "souris-MOUSE" twice but the unknown translation "hibou-OWL" once, the cue word souris will have a higher familiarity than the cue word hibou (Reder \& Ritter, 1992). As noted previously, young and older adults have been observed to have similar selection strategies when learning an unfamiliar language (Price et al., 2010), therefore changes in cue familiarity should be equivalent between the two age groups. Item differences in cue familiarity can be used by young and older adults to inform their FOK judgments, thereby reducing the effect of impaired target accessibility in the older adult group. The increased diagnostic value of cue familiarity could consequently lead to a reduced deficit in episodic FOK accuracy in the older adult group, whereby performance is not significantly above chance but is not significantly below that of the young adults, as observed on the current study.

One characteristic of the data in the present study which is surprising is the lack of an age-related deficit in episodic memory. Episodic memory impairments in older adults are well documented, with deficits in the use of 
self-initiated processes (Light \& Singh, 1987) and associative binding mechanisms (Naveh-Benjamin et al., 2007) thought to be among the possible contributors. In contrast semantic memory processes are relatively spared (Anderson \& Craik, 2000; Zacks et al., 2000), and the recruitment of these preserved semantic processes could be responsible for the equivalence in episodic memory performance of the young and older adults found in this experiment. Indeed, while standard word-pair learning can only be achieved via episodic associative memory processes, language learning will involve the formation of links with semantic memory as well as episodic memory processes. The Revised Hierarchical Model (RHM) of bilingual memory (Kroll \& Stewart, 1994) proposes that novice bilinguals initially rely on the episodic word-to-word associations and, as proficiency increases, shift to semantic-based words to concept associations. This shift from episodic to semantic based processing has been observed in young and older adults (Service \& Craik, 1993), and although the timing of the shift was not specified in the original model, early data indicated that episodic learning still occurred up to 2 years after commencement of learning (Kroll \& Curley, 1988). However, further studies have shown semantic-based processes being recruited in word learning even within a single study session (Altarriba \& Mathis, 1997; Papagnio et al., 1991). The present study was designed to encourage the use of episodic based learning processes by presenting the word forms at learning without any contextualising information, and by requiring participants to translate from the second language to the first language which, according to RHM utilises episodic, lexical level links (Sholl et al., 1995). Despite this it appears that semantic processes were still recruited during learning (consistent with the findings of Altarriba \& Mathis, 1997). Combined with the observation of superior semantic memory performance in the older adults, it is reasonable to suggest that the lack of episodic memory deficit within the current study is due to involvement of semantic processes during learning. Although speculative, the possible contribution of semantic memory processes to episodic tasks of similar design to the current study warrants further investigation. The greater level of semantic memory in the older adult group raises the issue of proficiency as a possible confound. To date, only three experiments have examined the role of expertise in FOK accuracy. Roberts and Rhodes (1989) showed no effect of self-rated expertise in the accuracy of FOKs for general knowledge information, a finding repeated by Marquié and Huet (2000) looking at self-efficacy beliefs for computer knowledge in young and older adults. Of direct interest to the current study, Peynircioğlu and Tekcan (2000) objectively measured language expertise and its effect on FOK ratings. They observed an increase in the magnitude of FOK ratings with increased expertise. However, the accuracy of FOK ratings showed no effect of expertise. Although participants with greater proficiency showed higher memory performance and were more confident in their ratings of future recognition, this was not predictive of their actual recognition performance. Taken together, these studies suggest that language expertise did not influence the accuracy of the FOK judgments within the present study.

One consideration with the present study is the small sample size used, affecting the confidence in which the present results may be interpreted. Indeed, the small sample size may be contributing to the lack of an interaction effect between memory and age in the semantic-episodic analysis. Despite this, the observed effect sizes of age on memory performance are of a more than acceptable level, and effect sizes regarding the FOK are also approaching a suitable standard. Thus the current study provides a well-founded novel methodology which may easily be replicated with a larger sample size to validate the current interpretation. In conclusion, these results demonstrate the difficulty in assessing the role of aging on episodic and semantic FOK accuracy. In particular, issues with task characteristics may be affecting our efforts to independently measure the two types of memory and their corresponding FOKs. The challenge for future research is to separate these two memory processes more completely in order to identify the presence, or indeed absence, of metacognitive deficits in aging.

\section{References}

Allen-Burge, R., \& Storandt, M. (2000). Age Equivalence in Feeling-of-knowing Experiences. Journal of Gerontology: Psychological Sciences, 55, 214-223. http://dx.doi.org/10.1093/geronb/55.4.P214

Altarriba, J., \& Mathis, K. M. (1997). Conceptual and Lexical Development in Second Language Acquisition. Journal of Memory and Language, 36, 550-568. http://dx.doi.org/10.1006/jmla.1997.2493

Anderson, N. D., \& Craik, F. I. M. (2000). Memory in the aging brain. In E. Tulving, \& F. I. M. Craik (Eds.), The Oxford Handbook of Memory. Oxford University Press; New York.

Bugaiska, A., Clarys, D., Jarry, C., Taconnat, L., Tapia, G., Vanneste, S., \& Isingrini, M. (2007). The Effect of Aging in Recollective Experience: The Processing Speed and Executive Functioning Hypothesis. Consciousness and Cognition, 16, 797-808. http://dx.doi.org/10.1016/j.concog.2006.11.007

Butterfield, E. C., Nelson, T. O., \& Peck, V. (1988). Developmental Aspects of the Feeling-of-knowing. Developmental Psychology, 24, 654-663. http://dx.doi.org/10.1037/0012-1649.24.5.654 
Carroll, M., \& Nelson, T. O. (1993). Effect of Overlearning on the Feeling of Knowing is more Detectable in Within-subject than Between-subject Designs. American Journal of Psychology, 106, 227-235. http://dx.doi.org/10.2307/1423169

Content, A., Mousty, P., \& Radeau, M. (1990). Brulex: Une Base de Donnés Lexicales Informatisée pour le Français Écrit et Parlé. L'Année Psychologique, 90, 551-566. http://dx.doi.org/10.3406/psy.1990.29428

Courtney, S. M., Ungerleider, L. G., Keil, K., \& Haxby, J. V. (1996). Object and Spatial Visual Working Memory Activate Separate Neural Systems in Human Cortex. Cerebral Cortex, 6(1), 39-49. http://dx.doi.org/10.1093/cercor/6.1.39

Department for Education and Skills. (2003). Secondary Schools Curriculum and Staffing Survey.

Folstein, M. F., Folstein, S. E., \& McHugh, P. R. (1975). Mini-mental State: Practical Method for Grading Cognitive State of Patients for Clinician. Journal of Psychiatric Research, 12(3), 189-198. http://dx.doi.org/10.1016/0022-3956(75)90026-6

Friedman, D., de Chastelaine, M., Nessler, D., \& Malcolm, B. (2010). Changes in Familiarity and Recollection Across the Lifespan: An ERP Perspective. Brain Research, 1310, 124-141. http://dx.doi.org/10.1016/j.brainres.2009.11.016

Gold, J. M., Berman, K. F., Randolph, C., Goldberg, T. E., \& Weinberger, D. R. (1996). PET Validation of a Novel Prefrontal Task: Delayed Response Alternation. Neuropsychology, 10(1), 3-10. http://dx.doi.org/10.1037/0894-4105.10.1.3

Hart, J. T. (1965). Memory and the Feeling-of-knowing Experience. Journal of Educational Psychology, 56, 208-216. http://dx.doi.org/10.1037/h0022263

Henkel, L. A., Johnson, M. K., \& De Leonardis, D. M. (1998). Aging and Source Monitoring: Cognitive Processes and Neuropsychological Correlates. Journal of Experimental Psychology: General, 127(3), 251-268. http://dx.doi.org/10.1037/0096-3445.127.3.251

Hertzog, C., Dunlosky, J., \& Sinclair, S. M. (2010). Episodic Feeling of Knowing Resolution Derives from the Quality of the Original Encoding. Memory and Cognition, 38(6), 771-784. http://dx.doi.org/10.3758/MC.38.6.771

Hicks, J. L., \& Marsh, R. L. (2002). On Predicting the Future States of Awareness for Recognition of Unrecallable Items. Memory \& Cognition, 30(1), 60-66. http://dx.doi.org/10.3758/BF03195265

Janowsky, J. S., Shimamura, A. P., \& Squire, L. R. (1989). Memory and Metamemory: Comparisons Between Patients with Frontal-lobe Lesions and Amnesic Patients. Psychobiology, 17(1), 3-11.

Jonides, J., Smith, E. E., Koeppe, R. A., Awh, E., Minoshima, S., \& Mintun, M. A. (1993). Spatial Working Memory in Humans as Revealed by PET. Nature, 363(6430), 623-625. http://dx.doi.org/10.1038/363623a0

Koriat, A. (1975). Phonetic Symbolism and Feeling of Knowing. Memory and Cognition, 3(5), 545-548. http://dx.doi.org/10.3758/BF03197529

Koriat, A. (1993). How Do We Know What We Know? The Accessibility Model of the Feeling of Knowing. Psychological Review, 100, 609-639. http://dx.doi.org/10.1037/0033-295X.100.4.609

Koriat, A. (1997). Monitoring One's Own Knowledge During Study: A Cue-utilisation Approach to Judgments of Learning. Journal of Experimental Psychology: General, 4, 349-370. http://dx.doi.org/10.1037/0096-3445.126.4.349

Koriat, A., \& Levy-Sadot, R. (2001). The Combined Contributions of Cue Familiarity and Accessibility Heuristics to Feelings of Knowing. Journal of Experimental Psychology: Learning, memory and Cognition, 27(1), 34-53. http://dx.doi.org/10.1037/0278-7393.27.1.34

Krinsky, R., \& Nelson, T. O. (1985). The Feeling of knowing for Different Types of Retrieval Failure. Acta Psychologica, 58, 141-158. http://dx.doi.org/10.1016/0001-6918(85)90004-6

Kroll, J. F., \& Curley, J. (1988). Lexical memory in novice bilinguals: The role of concepts in retrieving second language words. In M. Gruneberg, P. Morris, \& R. Sykes (Eds.), Practical Aspects of Memory (vol. 2). London: Wiley.

Kroll, J. F., \& Stewart, E. (1994). Category Interference in Translation and Picture Naming: Evidence for Asymmetric Connections Between Bilingual Memory Representations. Journal of Memory and Language, 33, 149-174. http://dx.doi.org/10.1006/jmla.1994.1008 
Light, L. L., \& Singh, A. (1987). Implicit and Explicit Memory in Young and Older Adults. Journal of Experimental Psychology: Learning, Memory and Cognition, 13, 531-541. http://dx.doi.org/10.1037/0278-7393.13.4.531

MacLaverty, S. N., \& Hertzog, C. (2009). Do Age-related Differences in Episodic Feeling of Knowing Accuracy Depend on the Timing of the Judgment? Memory, 17(8), 860-873. http://dx.doi.org/10.1080/09658210903374537

Maki, R. H. (1999). The Roles of Competition, Target Accessibility and Cue Familiarity in Metamemory for Word Pairs. Journal of Experimental Psychology: Learning, Memory and Cognition, 25(4), 1011-1023. http://dx.doi.org/10.1037/0278-7393.25.4.1011

Marquié, J. C., \& Huet, N. (2000). Age Differences in Feeling-of-knowing and Confidence Judgements as a Function of Knowledge Domain. Psychology and Aging, 15(3), 451-461. http://dx.doi.org/10.1037/0882-7974.15.3.451

Masson, M. E. J., \& Rotello, C. M. (2009). Sources of Bias in the Goodman-Kruskal Gamma Coefficient Measure of Association: Implications for Studies of Metacognitive Processes. Journal of Experimental Psychology: Learning, Memory and Cognition, 35(2), 509-527. http://dx.doi.org/10.1037/a0014876

McCarthy, G., Blamire, A. M., Puce, A., Nobre, A. C., Bloch, G., Hyder, F., ... Shulman, R. G. (1994). Functional Magnetic-resonance-imaging of Human Prefrontal Cortex Activation During a Spatial Working Memory Task. Proceedings of the National Academy of Sciences of the United States of America, 91(18), 8690-8694. http://dx.doi.org/10.1073/pnas.91.18.8690

Naveh-Benjamin, M., Brav, T., \& Levy, O. (2007). The Associative Memory Deficit of Older Adults: The Role of Strategy Utilisation. Psychology and Aging, 22, 202-208. http://dx.doi.org/10.1037/0882-7974.22.1.202

Nelson, T. O. (1984). A Comparison of Current Measures of the Accuracy of Feeling of Knowing Predictions. Psychological Bulletin, 95(1), 109-133. http://dx.doi.org/10.1037/0033-2909.95.1.109

Nelson, T. O., \& Narens, L. (1990). Metamemory: A theoretical framework and new findings. In G. H. Bower (Ed.), The psychology of learning and motivation: Advances in research and theory (pp. 125-173). New York: Academic Press.

Nelson, T. O., \& Narens, L. (1994). Why investigate metacognition? In J. Metcalfe, \& A. P. Shimamura (Eds.), Metacognition: Knowing about knowing (pp. 1-25). Cambridge, MA: MIT Press.

Nelson, T. O., Gerler, D., \& Narens, L. (1984). Accuracy of Feeling of knowing Judgments for Predicting Perceptual Identification and Relearning. Journal of Experimental Psychology: General, 113(2), 282-300. http://dx.doi.org/10.1037/0096-3445.113.2.282

Nelson, T. O., Leonesio, R. J., Shimamura, A. P., Landhwehr, R. F., \& Narens, L. (1982). Overlearning and the Feeling of Knowing. Journal of Experimental Psychology: Learning, Memory and Cognition, 8(4), 279-288. http://dx.doi.org/10.1037/0278-7393.8.4.279

Owen, A. M., Evans, A. C., \& Petrides, M. (1996). Evidence for a Two Stage Model of Spatial Working Memory Processing Within the Lateral Frontal Cortex: A Positron Emission Tomography Study. Cerebral Cortex, 6(1), 31-38. http://dx.doi.org/10.1093/cercor/6.1.31

Pannu, J. K., Kaszniak, A. W., \& Rapcsak, S. Z. (2005). Metamemory for Faces Following Frontal Lobe Damage. Journal of the International Neuropsychology Society, 11(6), 668-676. http://dx.doi.org/10.1017/S1355617705050873

Papagnio, C., Valentine, T., \& Baddeley, A. (1991). Phonological Short-term Memory and Foreign-language Vocabulary Learning. Journal of Memory and Language, 30, 331-347. http://dx.doi.org/10.1016/0749-596X(91)90040-Q

Perfect, T. J., \& Stollery, B. (1993). Memory and Metamemory Performance in Older Adults: One Deficit or Two? The Quarterly Journal of Experimental Psychology, 46(1), 119-135. http://dx.doi.org/10.1080/14640749308401069

Perrotin, A., Isingrini, M., Souchay, C., Clarys, D., \& Taconnat, L. (2006). Episodic Feeling-of-knowing Accuracy and Cued Recall in the Elderly: Evidence for Double Dissociation Involving Executive $\begin{array}{llllll}\text { Functioning and Processing Speed. Acta Psychologica, } & \text { 122, }\end{array}$ http://dx.doi.org/10.1016/j.actpsy.2005.10.003 
Perrotin, A., Tournelle, L., \& Isingrini, M. (2008). Executive Functioning and Memory as Potential Mediators of the Episodic Feeling of Knowing Accuracy. Brain and Cognition, 67(1), 76-87. http://dx.doi.org/10.1016/j.bandc.2007.11.006

Petrides, M., Alivisatos, B., Meyer, E., \& Evans, A. C. (1993). Functional Activation of the Human Frontal Cortex During the Performance of Verbal Working Memory Tasks. Proceedings of the National Academy of Sciences of the United States of America, 90(3), 878-882. http://dx.doi.org/10.1073/pnas.90.3.878

Peynircioğlu, Z. F., \& Tekcan, A. İ. (2000). Feeling of Knowing for Translations of Words. Journal of Memory and Language, 43, 135-148. http://dx.doi.org/10.1006/jmla.2000.2704

Pinon, K., Allain, P., Kefi, M. Z., Dubas, F., \& Le Gall, D. (2005). Monitoring Processes and Metamemory Experience in Patients with Dysexecutive Syndrome. Brain and Cognition, 57(2), 185-188. http://dx.doi.org/10.1016/j.bandc.2004.08.042

Price, J., Hertzog, C., \& Dunlosky, J. (2010). Self-regulated Learning in Younger and Older Adults: Does Aging Affect Metacognitive Control? Aging, Neuropsychology and Cognition, 17, 329-359. http://dx.doi.org/10.1080/13825580903287941

Raz, N. (2000). Aging of the brain and its impact on cognitive performance: Integration of structural and functional findings. In F. I. M. Craik, \& T. A. Salthouse (Eds.), The Handbook of Ageing and Cognition (2nd ed.). London: Lawrence Erlbaum Associates, Publishers.

Reder, L., \& Ritter, F. (1992). What Determines Initial Feeling of Knowing? Familiarity with Question Terms, not with the Answer. Journal of Experimental Psychology: Learning, Memory and Cognition, 18(3), 435-451. http://dx.doi.org/10.1037/0278-7393.18.3.435

Roberts, L. S., \& Rhodes, G. (1989). Knowing your Limits: Expertise and the Feeling of Knowing. New Zealand Journal of Psychology, 18(2), 71-75.

Schacter, D. L. (1983). Feeling of Knowing in Episodic Memory. Journal of Experimental Psychology: Learning, Memory and Cognition, 9, 39-54. http://dx.doi.org/10.1037/0278-7393.9.1.39

Schnyer, D. M., Nicholls, L., \& Verfaellie, M. (2005). The Role of VMPC in Metamemorial Judgments of Content Reliability. Journal of Cognitive Neuroscience, 17(5), 832-846. http://dx.doi.org/10.1162/0898929053747694

Schraw, G. (1995). Measures of Feeling of Knowing: A New Look at an Old Problem. Applied Cognitive Psychology, 9(4), 321-332. http://dx.doi.org/10.1002/acp.2350090405

Schwartz, B. L., \& Metcalfe, J. (1992). Cue Familiarity but not Target Retrievability Enhances Feeling of Knowing Judgments. Journal of Experimental Psychology: Learning, Memory and Cognition, 18(5), 1074-1083. http://dx.doi.org/10.1037/0278-7393.18.5.1074

Service, E., \& Craik, F. I. M. (1993). Differences Between Young and Older Adults in Learning a Foreign Vocabulary. Journal of Memory and Language, 32, 608-632. http://dx.doi.org/10.1006/jmla.1993.1031

Sholl, A., Sankaranarayanan, A., \& Kroll, J. F. (1995). Transfer Between Picture Naming and Translation: A Test of Asymmetries in Bilingual Memory. Psychological Science, 6, 45-49. http://dx.doi.org/10.1111/j.1467-9280.1995.tb00303.x

Smith, E. E., \& Jonides, J. (1999). Neuroscience: Storage and Executive Processes in the Frontal Lobes. Science, 283(5408), 1657-1661. http://dx.doi.org/10.1126/science.283.5408.1657

Smith, E. E., Jonides, J., Koeppe, R. A., Awh, E., Schumacher, E. H., \& Minoshima, S. (1995). Spatial Versus Object Working Memory: PET Investigations. Journal of Cognitive Neuroscience, 7(3), 337-356. http://dx.doi.org/10.1162/jocn.1995.7.3.337

Snodgrass, J. G., \& Corwin, J. (1988). Pragmatics of Measuring Recognition. Journal of Experimental Psychology: General, 117, 34-50. http://dx.doi.org/10.1037/0096-3445.117.1.34

Souchay, C., Isingrini, M., \& Espagnet, L. (2000). Aging, Episodic Memory Feeling-of-knowing, and Frontal Functioning. Neuropsychology, 2, 299-309. http://dx.doi.org/10.1037/0894-4105.14.2.299

Souchay, C., Moulin, C. J. A., Clarys, D., Taconnat, L., \& Isingrini, (2007). Diminished Episodic Memory Awareness in Older Adults: Evidence from Feeling-of-knowing and Recollection. Consciousness and Cognition, 16, 769-784. http://dx.doi.org/10.1016/j.concog.2006.11.002 
Sweeney, J. A., Mintun, M. A., Kwee, S., Wiseman, M. B., Brown, D. L., Rosenberg, D. R., \& Carl, J. R. (1996) Positron Emission Tomography Study of Voluntary Saccadic Eye Movements and Spatial Working Memory. Journal of Neurophysiology, 75(1), 454-468.

Thomas, A. K., Bulevich, J. B., \& Dubois, S. J. (2011). Context Affects Feeling-of-knowing Accuracy in Young and Older Adults. Journal of Experimental Psychology: Learning Memory and Cognition, 37(1), 96-108. http://dx.doi.org/10.1037/a0021612

Tulving, E. (1985). Memory and Consciousness. Canadian Psychology, 25, 1-12. http://dx.doi.org/10.1037/h0080017

Wright, D. B. (1996). Measuring Feeling of Knowing: A Comment on Schraw (1995). Applied Cognitive Psychology, 10(3), 261-268. http://dx.doi.org/10.1002/(SICI)1099-0720(199606)10:3<261:: AID-ACP387>3.0.CO;2-0

Yonelinas, A. P. (2002). The Nature of Familiarity and Recollection: A Review of 30 Years of Research. Journal of Memory and Language, 46(3), 441-517. http://dx.doi.org/10.1006/jmla.2002.2864

Zacks, R. T., Hasher, L., \& Li, K. Z. H. (2000). Human memory. In F. I. M. Craik, \& T. A. Salthouse (Eds.), The Handbook of Ageing and Cognition (2nd ed.). London: Lawrence Erlbaum Associates, Publishers.

\section{Notes}

Note 1. Years of education did not correlate with any outcome measures of memory or metacognitive performance therefore was not included as a covariate within the analysis.

Note 2. Note that despite the lower years of education in older adults, and matched level of French education, there is a tendency for the older adult group to outperform the young adults.

\section{Copyrights}

Copyright for this article is retained by the author(s), with first publication rights granted to the journal.

This is an open-access article distributed under the terms and conditions of the Creative Commons Attribution license (http://creativecommons.org/licenses/by/3.0/). 